\title{
Scopolamine but Not Lorazepam Modulates Face Repetition Priming: A Psychopharmacological fMRI Study
}

Christiane M. Thiel, Ph.D., Richard N.A. Henson, Ph.D., and Raymond J. Dolan, M.D.

Repetition priming is a basic form of learning associated with decreased neuronal responses following stimulus repetition. In this experiment, we address cholinergic and GABAergic modulation of repetition priming in a face recognition paradigm. In experiment 1 , we used eventrelated functional magnetic resonance imaging (fMRI) in combination with pharmacological challenge where participants were given placebo, lorazepam (2mg po), or scopolamine $(0.4 m g \mathrm{IV})$ prior to study. Behavioral data showed intact priming for famous faces in the placebo and lorazepam group but impaired priming following scopolamine. In within-group analyses, a right fusiform region showed a fame by repetition interaction characterized by a response decrease to repetition of famous faces and a response enhancement to repetition of unfamous faces in the placebo group. In subjects treated with lorazepam, a main effect of repetition, driven by response decreases to repetition of famous faces, was seen in this right fusiform region. No significant repetition effects were found after scopolamine. In experiment 2, we further investigated behaviorally the cholinergic impairment of repetition priming. Participants were given either placebo or scopolamine $(0.4 m g I V)$ after study. Behavioral data showed intact priming for famous faces in the placebo and scopolamine group. The results suggest that scopolamine but not lorazepam impair repetition priming for famous faces in a face recognition paradigm. These cholinergic impairments are likely to reflect interference with acquisition processes during study that may co-occur with a modulation of right fusiform decreases to repetition of famous faces.

[Neuropsychopharmacology 27:282-292, 2002] (C) 2002 American College of Neuropsychopharmacology. Published by Elsevier Science Inc.
KEY WORDS: fMRI; Priming; Scopolamine; Lorazepam; Psychopharmacology; Fusiform

From the Wellcome Department of Cognitive Neurology, Institute of Neurology, 12 Queen Square, London, WC1 3BG, UK (CMT, RNAH, RJD); Institute of Cognitive Neuroscience, University College London, London WC1E 6BT, UK (RNAH); and Royal Free Hospital School of Medicine, London NW3 2PF, UK (RJD).

Address correspondence to: Christiane M. Thiel, Ph.D., Institut für Medizin (IME), AG Kognitive Neurologie, Forschungszentrum Juelich, Leo-Brandt-Str. 5, 52425 Juelich, Germany, Tel.: + 2461-612483, Fax: + 2461-61-2820, E-mail: c.thiel@fz-juelich

Received May 9, 2002; revised December 20, 2001; accepted January 8, 2002.

Online publication: $2 / 25 / 02$ at www.acnp.org/citations/ Npp022502248.
Repetition priming is a basic form of learning defined behaviorally as facilitated or biased processing of previously encountered stimuli. One possible neuronal signature of this form of learning is "response suppression," a decrement in the neuronal response to repeated stimulation that has been shown in monkeys (Desimone 1996). Measures of repetition priming in humans include pattern completion, object identification, or word-stem completion tasks (Schacter 1994). When using such tasks in conjunction with neuroimaging methods, studies have consistently found decreased hemodynamic responses in posterior cortical regions when items are repeated (Squire et al. 1992; Buckner et al. 1998; Buckner et al. 2000; Badgaiyan 2000; van Turennout et al. 2000). Thus, neuroimaging methods have 
successfully demonstrated a human analog to the decreased neural firing observed in monkey cortex, which is referred to as "repetition suppression."

Using a word-stem completion task, we have previously shown that "repetition suppression" is modulated by GABAergic and cholinergic neurotransmitter systems (Thiel et al. 2001). Both lorazepam and scopolamine decreased the size of repetition suppression effect in posterior and frontal cortical regions. Both drugs also impaired the behavioral index of repetition priming, suggesting that GABAergic and cholinergic systems modulate neuronal plasticity necessary for priming in this paradigm. The behavioral impairments with lorazepam were consistent with prior studies using picture-fragment completion, word-fragment completion, or wordstem completion tasks (Legrand et al. 1995; Vidailhet et al. 1994; Vidailhet et al. 1999; Danion et al. 1992; Brown et al. 1989). Behavioral impairments of repetition priming with scopolamine, on the other hand, were not in line with the majority of prior studies (Knopman 1991; Danion et al. 1990; Schifano and Curran 1994), and we suggested that these differences could be caused by a lower active dose used in these previous studies (see Thiel et al. 2001 for discussion).

The rationale for the present study was to further investigate GABAergic and cholinergic modulation of repetition priming, using a paradigm involving face recognition (Ellis et al. 1990). This paradigm investigates priming of faces and its modulation by familiarity (i.e., famous vs. unfamous faces). Whereas the paradigm has been used in several psychological and neuroimaging studies (Ellis et al. 1990; Brunas-Wagstaff et al. 1992; Henson et al. 2000; Henson et al. 2002), its pharmacological modulation has not previously been investigated. Functional magnetic resonance imaging (fMRI) studies using repeated, intermixed presentations of famous and unfamous faces in implicit face priming paradigms have shown greater responses to famous than unfamous faces in bilateral fusiform cortex and repetition-related responses to faces in a right fusiform region that were sensitive to stimulus familiarity (Henson et al. 2000; Henson et al. in press). This modulation by stimulus familiarity was seen in an attenuation of responses to repetition of famous faces and, depending on whether a direct or indirect monitoring task was used, an enhanced (Henson et al. 2000) or unchanged (Henson et al. 2002) response to repetition of unfamous faces.

Because prior studies presented faces repeatedly in an intermixed manner, they confounded repetition effects with time effects (i.e., first presentation occurs always before second presentation). Therefore, the first aim of the present experiment was to replicate the fame and fame by repetition-dependent fusiform responses with a face priming paradigm that avoided potential confounds. Following the study by Henson et al. (in press), two planned comparisons were performed identifying (1) fusiform regions with greater responses to famous than unfamous faces, and (2) fusiform regions showing an interaction between fame and repetition. A second aim was then to examine whether lorazepam and/or scopolamine would modulate the behavioral measure of priming and associated responses in these identified fusiform regions. A third aim was to identify whether drug-induced impairments are caused by the drugs' actions during study or test phase.

\section{METHODS}

We performed a psychopharmacolgocial fMRI study (experiment 1), followed by a further psychopharmacological experiment (experiment 2).

\section{Experiment 1}

Subjects. Forty-seven right-handed native Englishspeaking participants ( 29 male, 18 female; age range: 18-37 years), with no history of medical or psychiatric disease, gave informed consent to participate in the study. The same subjects were also tested on a wordstem completion paradigm (Thiel et al. 2001). Thirteen participants were excluded from analysis. Exclusion criteria were technical failure $(n=5)$, excessive head movement $(n=1)$, or less than $50 \%$ correct responses to either famous or unfamous faces $(n=7)$. Failure to correctly identify the faces occurred in all groups (placebo $n=1$, lorazepam $n=3$, scopolamine $n=3$ ). Those volunteers did not differ demographically from the other volunteers.

Drugs. A double-blind, double-dummy, time-elapsed drug administration technique was used so that each subject received a tablet orally and an injection IV, 120 min and $80 \mathrm{~min}$ respectively, before the start of the study phase, i.e.: (1) placebo orally + saline IV $(n=12)$, (2) $2 \mathrm{mg}$ lorazepam orally + saline iv $(\mathrm{n}=11)$; and (3) placebo orally $+0.4 \mathrm{mg}$ scopolamine IV $(\mathrm{n}=11)$. Drug doses and administration schedules were chosen according to the literature in a manner designed to optimize behavioral impairments. Thus, doses between 2 and $3 \mathrm{mg}$ oral lorazepam have been shown to reliably impair repetition priming, whereas lower doses are less effective (Buffett-Jerrott et al. 1998; Legrand et al. 1995; Knopman 1991), with maximal effects occurring at $2 \mathrm{~h}$ after ingestion which also corresponds to peak plasma levels (Legrand et al. 1995). Scopolamine was administered IV because oral scopolamine has variable absorption, poor bioavailability, and is behaviorally less effective (Putcha et al. 1989; Nuotto 1983). The dose of scopolamine was chosen because IV injections in this dose range have been reported to affect a variety of cog- 
nitive functions (Sunderland et al. 1987; Martinez et al. 1997; Vitiello et al. 1997). Scopolamine was administered $80 \mathrm{~min}$ before scanning, as prior studies have shown that cognitive effects of parenteral scopolamine peaks from 90 to $150 \mathrm{~min}$ after administration (Safer and Allen 1971; Sannita et al. 1987; Curran et al. 1991; Ebert et al. 1998).

Experimental Design. The experiment employed a two-by-two factorial design in which the events of interest were first or second presentation of famous (F1 and F2) and unfamous (U1 and U2) faces. Stimuli were 100 gray-scale photographs, consisting of 50 famous and 50 unfamous faces. They were randomly divided into two sets of 50 faces, containing equal numbers of famous and unfamous faces. The famous faces correspond to those used by Gorno-Tempini et al. (1998). She presented 200 black-and-white photographs to a group of young (age 18-33) subjects and selected the 56 faces that $95 \%$ of the subjects could name. The unfamiliar faces were matched for sex and age. The expression of both types of faces was generally neutral or smiling. The resulting images were cropped by an oval, and approximately matched for size and illumination. In a study phase, conducted outside the scanner, and following drug or placebo administration, subjects were presented visually with one or other set of 50 faces. Faces were displayed for $1 \mathrm{~s}$ against a baseline checkerboard every $4 \mathrm{~s}$ on a Macintosh computer, and participants were asked to make a fame judgment as quickly and accurately as possible by pressing one of two response keys. Scanning took place during a subsequent test phase in which subjects were presented with the whole set of 100 faces, containing randomly intermixed famous and unfamous faces that were either presented in the study phase (F2 and U2) or were not (F1 and U1). Stimuli, including 50 "nullevents" (Josephs and Henson 1999), were again displayed for $1 \mathrm{~s}$ every $4 \mathrm{~s}$ on a Macintosh computer, projected onto a screen approximately $300 \mathrm{~mm}$ above the participant in the MRI scanner (see Figure 1). Participants were asked to make a fame judgment by pressing one of two response keys (e.g., Ellis et al. 1990). The mean correct reaction times for first versus second presentation of famous and unfamous faces provided a behavioral index of repetition priming. Finally, prior to behavioral testing, subjective sedation was assessed with visual analog scales (Bond and Lader 1974).

Data Acquisition. A VISION MRI system (Siemens, Erlangen, Germany) operating at 2T was used to obtain T2*-weighted echoplanar (EPI) images $\left(64 \times 64,3 \times 3 \mathrm{~mm}^{2}\right.$ pixels) with blood oxygenation level-dependent (BOLD) contrast. 250 volumes of $302 \mathrm{~mm}$-thick axial slices were acquired sequentially every $3.5 \mathrm{~mm}$ (repetition time = $2.5 \mathrm{~s}$, echo time $=40 \mathrm{~ms}$ ). The first 5 volumes were discarded to allow for T1 equilibration effects. Images

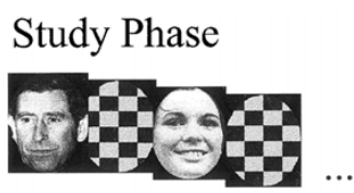

Test Phase during Scanning

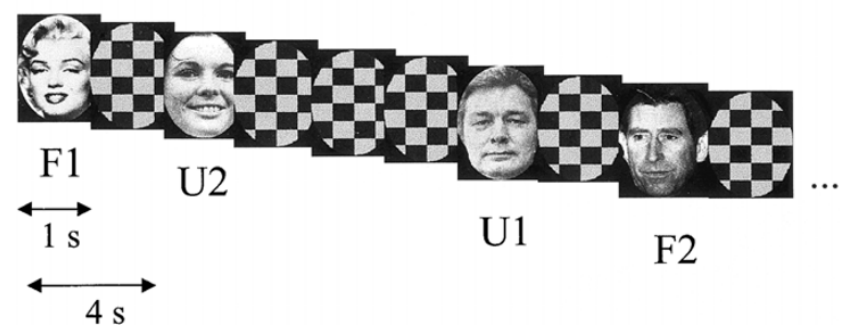

Figure 1. Experimental paradigm. Illustration of stimuli presented during study and test phases. Test stimuli were either famous or unfamous faces that were either presented in the study phase or were not. Stimuli were randomly displayed every $4 \mathrm{~s}$ for $1 \mathrm{~s}$ against a baseline of checkerboards.

were realigned to correct for interscan movement, synchronized to the middle slice to correct for differences in slice acquisition time, and normalized to a standard EPI template volume. The data were then smoothed with a Gaussian kernel of $8 \mathrm{~mm}$ full-widthhalf-maximum to accommodate intersubject anatomical variability.

Data Analysis. Data were analyzed with Statistical Parametric Mapping software (SPM99, Wellcome Department of Cognitive Neurology, London; Friston et al. 1995), employing a random effects analysis. Data were globally scaled to 100 across scans and highpassfiltered at $1 / 60 \mathrm{~Hz}$. The hemodynamic response to stimulus onset for each event type was modeled by a canonical synthetic hemodynamic response function (HRF) and its first-order temporal derivative. Seven event types were modeled: Four effects of interest for first and second presentation of famous (F1, F2) and unfamous (U1, U2) faces that were correctly identified and three effects of no interest (two for incorrect responses to famous and unfamous faces and one for missed responses). The six head movement parameters were included as confounds. At the first level, linear contrasts of parameter estimates for each subject were taken to a second-level analysis to generate statistical parametric maps of the t-statistic. A statistical parametric map (thresholded at $p<.001$ ) of voxels showing significant responses to stimulus presentation versus baseline was created. This mask was then used to identify through two planned comparisons in each group (1) brain regions showing greater responses to famous than unfamous faces, and (2) brain regions showing an interaction between fame and repetition (see Henson et al. in press). For predicted effects in fusiform gyrus, the 
threshold of significance was set at $p<.001$, uncorrected. Additionally, peak signal change for the effect maxima in the placebo group was plotted for each drug condition and analyzed with analyses of variance (ANOVAs) for repeated measures followed post hoc by two-tailed $t$ tests (threshold of significance was set at $p<.05$ ). Group differences between placebo and each drug condition were investigated with $2 \times 2$ (group by fame) or $2 \times 2 \times$ 2 (group by fame by repetition) way ANOVAs for repeated measures for voxels showing fame and fame by repetition interactions, respectively. Behavioral data were analyzed with ANOVAs for repeated measures followed post hoc by two-tailed $t$-tests (threshold of significance was set at $p<.05$ ).

\section{Experiment 2}

Subjects. Twenty-six right-handed subjects (13 male, 13 female; age range: 18-36 years) participated in this psychopharmacological study.

Experimental Design and Drugs. The aim of this further experiment was to determine behaviorally whether scopolamine's impairment of famous face priming was caused by the drug's effects during study or test phase. The paradigm was the same as in experiment 1 but performed outside the scanner. Volunteers received either $0.4 \mathrm{mg}$ IV scopolamine $(\mathrm{n}=11)$ or placebo $(\mathrm{n}=15)$ after completion of the study phase, i.e., after information acquisition. Testing was performed $80 \mathrm{~min}$ after drug injection.

Data Analysis. Behavioral data were analyzed with ANOVAs for repeated measures, followed post hoc by two-tailed $t$-tests (threshold of significance was set at $p<.05)$.

\section{RESULTS}

\section{Behavior: Experiment 1}

Table 1 shows the percentage of correctly recognized faces. There were no significant group differences in correct responses to famous or unfamous faces (all ANOVAs $p>.05)$. In the placebo group, analysis of behavioral data (Figure 2, left panel) yielded a fame by repetition interaction $[\mathrm{F}(1,11)=8.39, p=.015]$. Priming was observed for famous faces [ $\mathrm{t}(11)=-4.403, p=.001]$ but not for unfamous faces [t(11)=.983, $p=.347]$. Priming was not abolished by lorazepam. Analysis of behavioral data yielded a fame by repetition interaction $[\mathrm{F}(1,10)=5.52, p=.041]$. As in the placebo group, priming was observed for famous faces [ $\mathrm{t}(11)=-4.094, p=$ $.002]$ but not for unfamous faces [ $\mathrm{t}(11)=.505, p=.625]$. There were no differences in the magnitude of priming for famous faces between lorazepam and placebo $(2 \times 2$ way ANOVA; group by repetition interaction $[\mathrm{F}(1,21)=$
Table 1. Percent Correct Responses

\begin{tabular}{lccc}
\hline & $\begin{array}{c}\text { Placebo } \\
(\mathbf{n}=\mathbf{1 2})\end{array}$ & $\begin{array}{c}\text { Lorazepam } \\
(\mathbf{n}=\mathbf{1 1})\end{array}$ & $\begin{array}{c}\text { Scopolamin } \\
\mathbf{e} \\
\mathbf{( n = 1 1 )}\end{array}$ \\
\hline F1 & $74.00 \pm 3.98$ & $72.00 \pm 4.48$ & $70.91 \pm 4.77$ \\
F2 & $83.67 \pm 3.36$ & $80.00 \pm 3.66$ & $74.91 \pm 5.03$ \\
U1 & $90.00 \pm 2.23$ & $84.36 \pm 4.05$ & $82.55 \pm 3.75$ \\
U2 & $91.00 \pm 1.78$ & $80.73 \pm 4.44$ & $82.18 \pm 3.67$ \\
\hline
\end{tabular}

$.808, p=.379]$. Scopolamine, on the other hand, abolished the behavioral index of priming. Data analysis showed no fame by repetition interaction $[\mathrm{F}(1,10)=1.13$, $p=.312]$ or repetition effects $[\mathrm{F}(1,10)=0.40, p=.542]$. In other words, the priming of famous faces that was observed in the placebo and lorazepam groups was not present after an anticholinergic drug challenge. When comparing priming for famous faces between scopolamine and placebo, a significant group by repetition interaction was found reflecting the absence of famous face priming under scopolamine compared with placebo $[2 \times 2$ way ANOVA, $\mathrm{F}(1,21)=4.689, p=.042]$.

\section{Behavior: Experiment 2}

The data in the placebo group replicated our prior behavioral results by showing a fame by repetition interaction $[\mathrm{F}(1,10)=5.833, p=.036$, Figure 3]. Again, priming was observed for famous $[\mathrm{t}(10)=-4.017, p=.002]$ but not for unfamous faces [t $(10)=-1.497, p=.165]$. In contrast with the first study, however, priming was intact when scopolamine was given after the study phase [main effect of repetition: $\mathrm{F}(1,14)=9.854, p=.007$, though it did not differ significantly for famous and unfamous faces [fame by repetition interaction, $\mathrm{F}(1,14)=2.302, p=.151]$. When comparing priming for famous faces in placebo and scopolamine groups, no significant differences were found in this experiment $(2 \times 2$ way ANOVA; group by repetition interaction $[\mathrm{F}(1,24)<.001 ., p=.993]$.

\section{Imaging}

Placebo. FAME. Greater responses to famous than unfamous faces were seen in left $(-51,-54,-24 \mathrm{Z}=3.22)$ and right fusiform cortex $(42,-60,-15 Z=3.19$, Figure $4)$. The right panel of Figure 4 shows percent signal change for famous and unfamous faces (irrespective of 1st or 2nd presentation) derived from the maximum voxel in the left fusiform region.

FAME BY REPETITION. A significant fame by repetition interaction was found in a region of right fusiform cortex (30, $-45,-30 ; Z=3.20$, Figure 2, middle panels), close to the regions previously identified by Henson et al. (2000, 2002). The plotted percent signal change de- 
Behavior

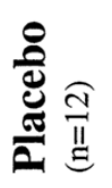

苋
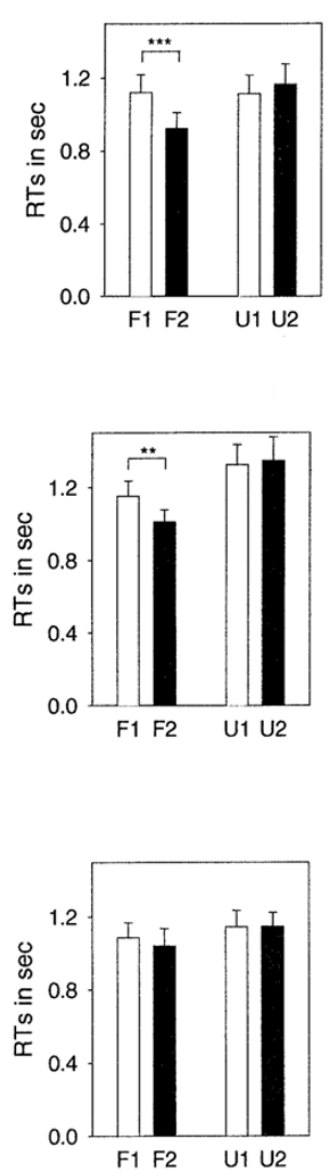

\section{Imaging \\ Fame by Repetition Interaction}
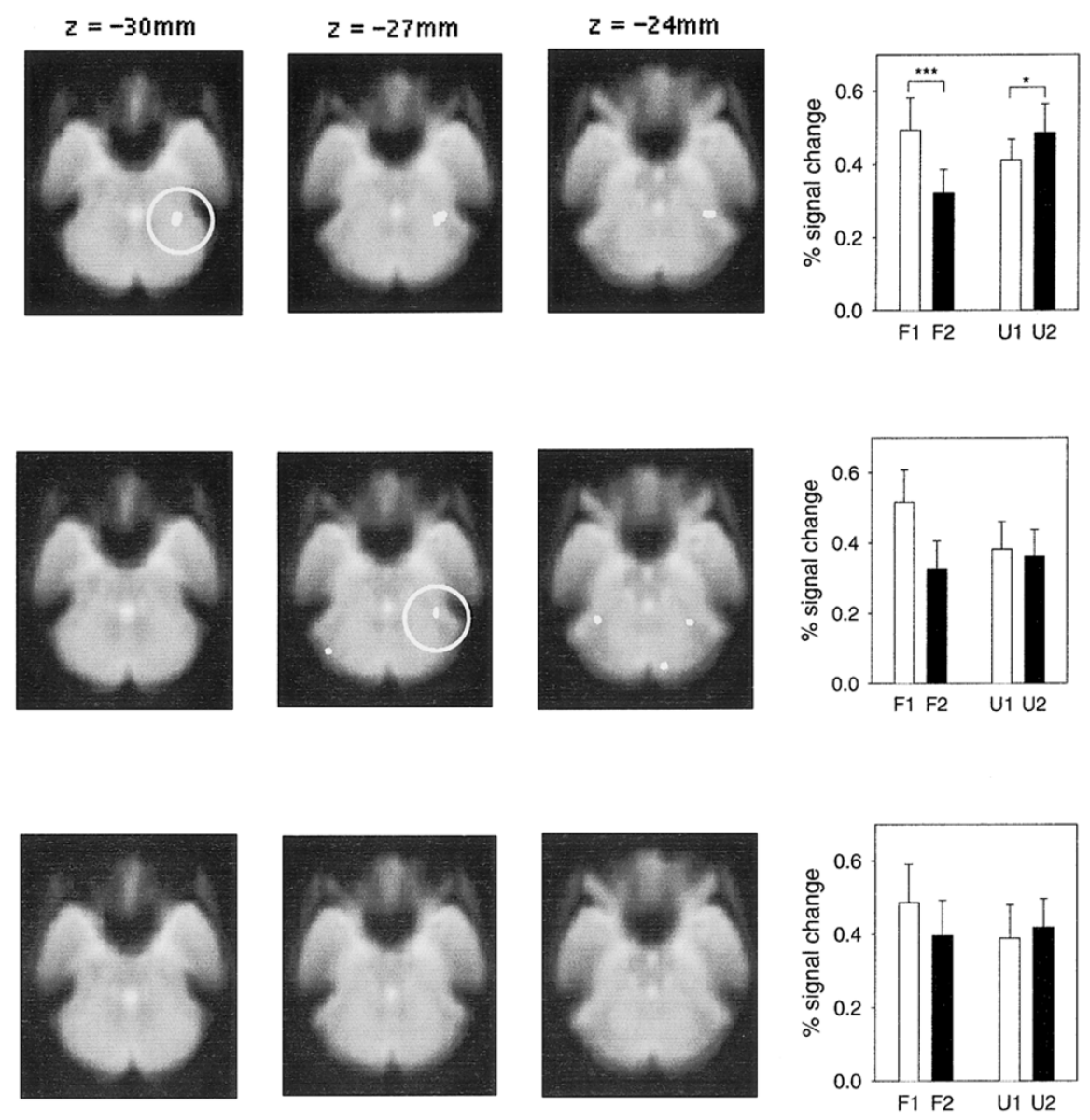

Figure 2. Left panel. Behavioral data experiment 1. Mean reaction times and standard errors for new famous (F1), old famous (F2), new unfamous (U1) and old unfamous (U2) faces for placebo (top row), lorazepam (middle row), and scopolamine group (bottom row). Data were analyzed with analyses of variance (ANOVAs) for repeated measures, with fame (famous vs. unfamous) and repetition (new vs. old) as a within-subject factor. Significant effects were followed post hoc by paired $t$-tests $\left({ }^{* *} p<.001,{ }^{* *} p<.01\right)$. Middle panels. Regions in fusiform cortex showing a fame by repetition interaction in the placebo (top row), lorazepam (middle row), and scopolamine group (bottom row). Activations are rendered on transverse mean normalized EPI images (EPI images averaged over several volunteers, activations thresholded at $p<.01$ for purposes of illustration). Right panel. Plots of percent signal change. Mean and SEM (standard error of mean) for new famous (F1), old famous (F2), new unfamous (U1), and old unfamous (U2) faces in the placebo, lorazepam, and scopolamine groups. The plots in all groups derive from the maximum voxel in the placebo group $(30,-45,-30)$ identified by random effects analysis. Data were analyzed with ANOVAs for repeated measures, with fame (famous vs. unfamous) and repetition (new vs. old) as a within-subject factor. Significant effects were followed post hoc by paired $t$-tests $\left({ }^{* *} p<.001,{ }^{*} p<.05\right)$.

rived from this voxel confirms the two-way interaction between fame and repetition $[\mathrm{F}(1,11)=18.019, p=.001$, Figure 2, right panel] and demonstrates that this interaction reflects repetition suppression to famous [ $t(11)=-$ $4.68 p=.001]$ and repetition enhancement to unfamous faces [ $\mathrm{t}(11)=2.350 p=.039]$.

To determine whether a similar pattern was seen in the previously identified fusiform region (voxel 36,-51,-24; Henson et al. 2002), we analyzed responses derived from that voxel. No fame by repetition interaction $[F(1$,
$11)=0.307, p=.591]$ or repetition effects $[\mathrm{F}(1,11)=1.327, p=$ .274] were found in this previously identified voxel.

Lorazepam. FAME. The only fusiform region showing greater responses to famous than unfamous faces was on the right $(42,-39,-27 \mathrm{Z}=3.77$; Figure 4$)$, anterior and ventral to the right fusiform activation seen in the placebo group. To determine whether fame effects under lorazepam were seen in the region that showed fame effects in the placebo group, percent signal change 

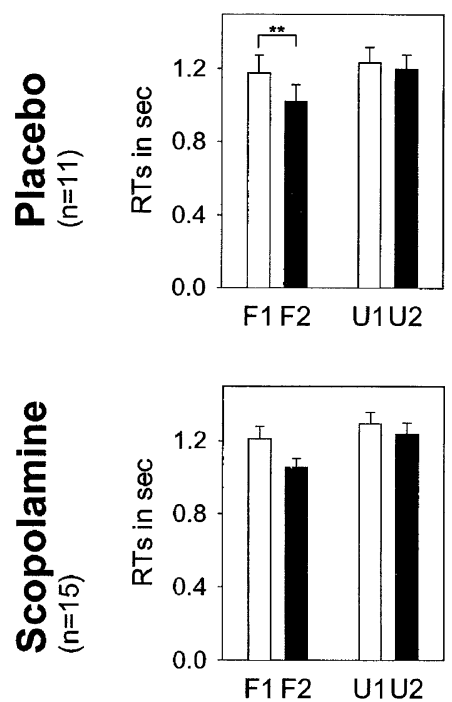

Figure 3. Behavioral data experiment 2. Mean reaction times and SEM in placebo and scopolamine groups when drug challenge was given after study phase (see Figure 2 for more details). Data were analyzed with ANOVAs for repeated measures, with fame (famous vs. unfamous) and repetition (new vs. old) as within-subject factors. Significant effects were followed post hoc by paired $t$-tests $\left({ }^{* *} p<.01\right)$.

derived from the left fusiform voxel that showed the strongest fame effect in the placebo group was plotted (Figure 4, right panel). Even though overall signal changes were low, this region still showed a significant fame effect after lorazepam $[\mathrm{F}(1,10)=6.061, p=.034]$.

To determine whether there were significant group differences for activations in the left fusiform voxel $(-51,-54,-24)$ between placebo and lorazepam, a $2 \times$ 2 way ANOVA testing for drug and fame effects was performed. Analysis of percent signal change showed a significant difference between placebo and lorazepam [main effect drug $\mathrm{F}(1,21)=9.062, p=.007$ ], with smaller activations to both famous and unfamous faces under lorazepam. The same pattern was found for the maximum voxel previously identified by Henson et al. (2002) $[\mathrm{F}(1,21)=24.29, p<.001]$.

FAME By RePETITION. No region of fusiform cortex showed a significant fame by repetition interaction under lorazepam (Figure 2, middle panels). When we analyzed data derived from the voxel showing a fame by repetition interaction in the placebo group, however, a repetition effect, mainly driven by repetition suppression for famous faces, was observed $\mathrm{F}(1,10)=5.22, p=$ .045; Figure 2, right panel], though the fame by repetition interaction was not significant $[\mathrm{F}(1,10)=1.634, p=$ .230].

A $2 \times 2 \times 2$ ANOVA testing for drug, fame, and repetition effects between placebo and lorazepam did not show any group by fame by repetition interaction $[\mathrm{F}(1,21)=.294, p=.593]$.
Scopolamine. FAME. Greater responses to familiar than unfamiliar faces were seen in left fusiform cortex $(-45,-60,-24 \mathrm{Z}=3.33$; Figure 4) close to the region showing a fame effect in the placebo group. An analysis of the voxel showing a maximum effect in the placebo group revealed numerical but not statistically significant evidence for enhanced responses to famous compared with unfamous faces under scopolamine $[\mathrm{F}(1$, $10)=4.320, p=.064$; Figure 4, right panel]. As in the lorazepam group, overall signal changes were low.

To determine whether the left fusiform signal changes were significantly different under scopolamine, a $2 \times 2$ way ANOVA testing for drug and fame effects was performed. Analysis of percent signal change showed smaller activations to both famous and unfamous faces under scopolamine $[\mathrm{F}(1,21)=7.398, p=$ .013]. The same pattern was found for the maximum voxel previously identified by Henson et al. (2002) $[\mathrm{F}(1,21)=9.577, p=.005]$.

FAME BY REPETITION. Under scopolamine, there was no region with a significant fame by repetition interaction (Figure 2, middle panels). There were also no significant fame by repetition or repetition effects $[\mathrm{F}(1,10)=1.902, p=.198 ; \mathrm{F}(1,10)=.695, p=.424$; Figure 2, right panel] in the voxel showing a fame by repetition interaction in the placebo group and repetition effects under lorazepam.

To determine whether the lack of repetition effects was significantly different from placebo a $2 \times 2 \times 2$ way ANOVA was performed. The results of this analysis did not, however, yield a significant group by fame by repetition interaction $[\mathrm{F}(1,21)=1.516, p=.232]$.

\section{DISCUSSION}

The main finding of this study is that scopolamine, but not lorazepam, modulates the behavioral index of repetition priming within a face-priming paradigm. Furthermore, we suggest that the cholinergic modulation of repetition priming takes place during information acquisition. The imaging data of the study replicates the fame and fame by repetition interactions found previously in fusiform regions (Henson et al. 2002) and indicates a drug modulation of these fusiform responses.

\section{Possible Confounds}

One important consideration is the possibility that drugs, such as scopolamine, might affect global and/or regional cerebral blood flow (gCBF/rCBF). Tsukada et al. have shown in monkeys that $\mathrm{rCBF}$ to somatosensory stimulation is abolished by scopolamine (Tsukada et al. 1997). The doses shown to yield this effect were, however, 10 times higher than the dose used here, and of critical relevance is the fact that no effects on $\mathrm{rCBF}$ were 


\section{Fame Effects}
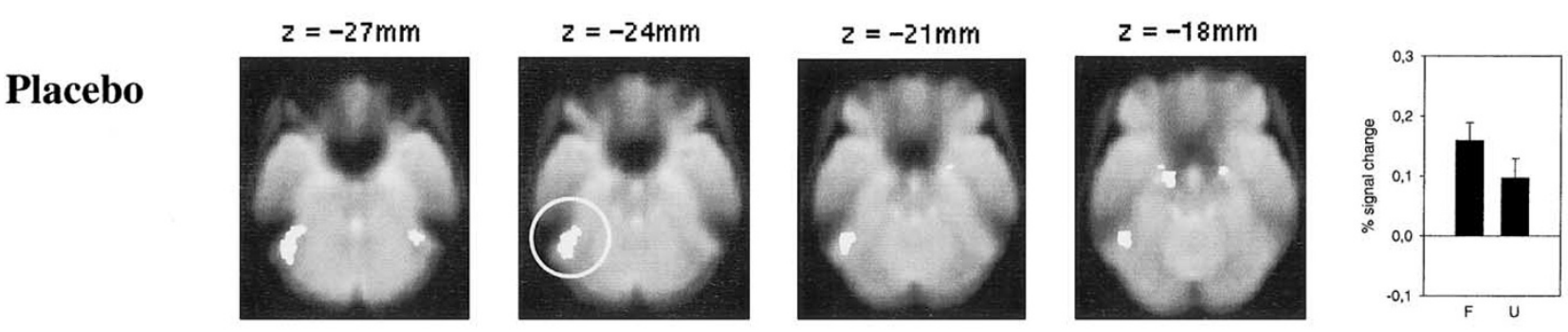

\section{Lorazepam}
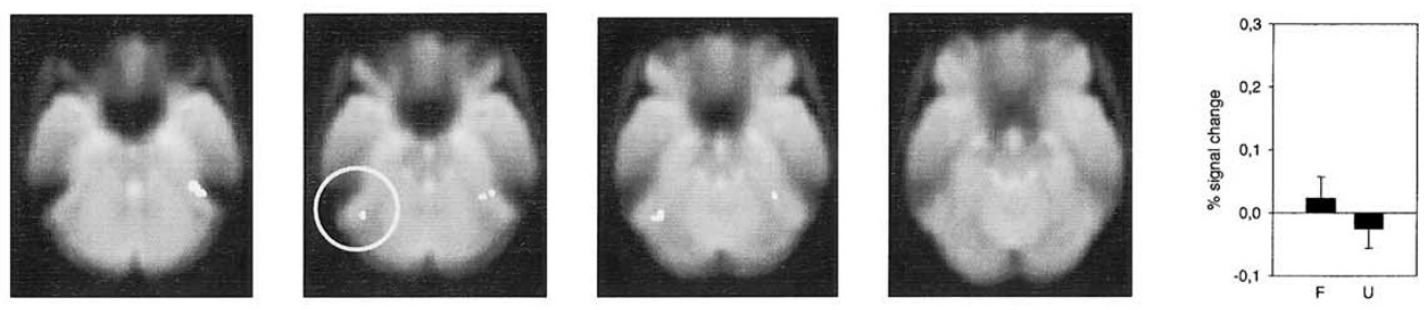

\section{Scopolamine}
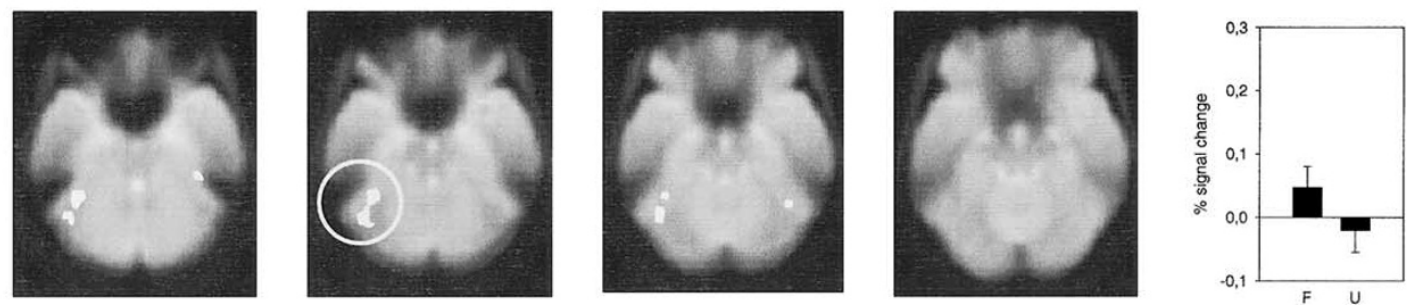

Figure 4. Left panels. Regions in fusiform cortex, showing greater activations to famous than to unfamous faces in the placebo, lorazepam, and scopolamine group (top, middle, bottom rows respectively, see Figure 2 for more details). Right panel. Plots of percent signal change. Mean and SEM for famous (F) and unfamous (U) faces in the placebo, lorazepam, and scopolamine groups irrespective of 1st or 2 nd presentation (top, middle, bottom rows, respectively). The plots in all groups derive from the maximum voxel in the placebo group $(-51,-54,-24)$ identified by random effects analysis.

found at a lower dose. To account for possible differences in gCBF between the groups in our data, global scaling was used in the data analysis. Furthermore, we found no evidence for a difference when we compared the estimated global BOLD signal between the drug groups, which makes significant changes in gCBF unlikely.

The decreased reaction times associated with priming might be considered a confound in that decreased reaction times may be the cause rather than the effect of neural changes. The finding, however, that reaction times to unfamous faces were slower than to famous faces and yet were associated with lower fusiform responses (which was especially evident in the lorazepam group) is not consistent with this explanation (for discussion of this confound see also Henson et al. in press).

Another behavioral confound common to drug studies is sedation. Drugs that impair memory often also induce sedation. Several psychopharmacological studies have tried to deal with sedation in different ways (e.g.,
Green et al. 1996; Martinez et al. 1997; Curran et al. 1991). Curran et al. (1991) investigated amnesic effects of scopolamine and lorazepam and included a control group that received an antihistamine with sedative but no memory impairing effects. As sedation was present with all three drugs but memory impairments only with scopolamine and lorazepam, they were able to conclude that the amnesic effects of those two drugs were not dependent on sedation. As a dissociation between scopolamine-induced amnesia and sedation was shown in previous studies (Martinez et al. 1997; Curran et al. 1991), we controlled only for sedation by assessing subjective measures of sedation (Bond and Lader 1974) and investigating a potential correlation with measures of priming. We correlated measures of sedation across all 34 subjects with the behavioral index of priming. There was no correlation between measures of sedation and reaction time differences for famous $(\mathrm{r}=-.267, p=$ $.115)$ or unfamous faces $(r=-.080, p=.653)$. 


\section{Behavior}

Placebo. Behavioral results in the placebo group replicate findings of prior priming studies by showing a fame by repetition interaction. A decrease in reaction times to repeated presentation of famous faces is a consistent finding, whereas effects of repetition to unfamous faces are typically not as large and are more variable (Ellis et al. 1990; Henson et al. 2002; GoshenGottstein and Ganel, 2000; Schweinberger et al. 1995). One explanation for these variable effects to unfamous faces is lag, ie., the time between the first and second presentation of a stimulus. It has been shown that priming of unfamiliar faces is sensitive to lag (Bentin and Moscovitch, 1988) and relatively long lag (approx. 40 min) between first and second presentation of faces in our study might account for a lack of priming to unfamous faces observed here.

Lorazepam. Our finding that lorazepam did not impair priming in a face recognition paradigm seems in contrast with most previous studies investigating the pharmacological modulation of repetition priming. Thus, lorazepam has been consistently shown to reduce behavioral indices of priming in several paradigms, including picture-fragment completion, word-fragment completion, and word-stem completion tasks (Legrand et al. 1995; Vidailhet et al. 1994; Vidailhet et al. 1999; Danion et al. 1992; Brown et al. 1989). We were able to replicate lorazepam's impairments on word-stem completion priming (Thiel et al. 2001) but were not able to find attenuated priming when using a face priming paradigm in the same volunteers. Intact priming in a face repetition paradigm would furthermore argue that effects of lorazepam in repetition priming paradigms are not due from interference with perceptual integration as previously suggested (e.g., Giersch et al. 1995).

Our data thus suggest that lorazepam's impairment of repetition priming depends on the priming task used and that different priming tasks can be dissociated pharmacologically. Dissociations between word-stem completion tasks and word-fragment or picture-naming tasks were previously found by manipulating attentional load during a study phase. Increased attentional load reduced repetition priming in word-stem completion but not in word-fragment or picture-naming tasks (Clarys et al. 2000; Gabrieli et al. 1999). A similar dissociation was found when testing Alzheimer patients, who were impaired on word-stem completion but not picture-naming or category exemplar identification (Gabrieli et al. 1999). The authors suggest that these effects can be explained by an identification-production distinction within these paradigms that might differ in their neural bases. In this respect, it is interesting that we found a dissociation between a production form of priming (word-stem completion) and an identification form of priming (face identification) after a GABAergic challenge. Further experiments are needed to address the precise mechanisms of our dissociation and how it compares with these previous, attention-dependent dissociations. Future experiments could also investigate whether priming paradigms using face stimuli, which bear social relevance, are less sensitive to GABAergic manipulations. Nonetheless, together with our previous study (Thiel et al. 2001), the present results are the first to show that priming can be dissociated pharmacologically, which underlines the idea that different priming tasks may rely on different neuronal or neurochemical systems.

Scopolamine. Our results showed impairments in a face-priming paradigm when scopolamine was given before study phase. Note that scopolamine did not affect task accuracy per se, as the number of correctly identified faces in this group did not differ from placebo or lorazepam. This argues against the idea that a perceptual mechanism underlies priming impairments after scopolamine and is consistent with a prior study showing that scopolamine does not affect face recognition (Rammsayer et al. 2000).

Prior psychopharmacological studies were not able to induce impairments in priming paradigms when giving scopolamine before study phase (Knopman 1991; Danion et al. 1990; Schifano and Curran, 1994) (see Thiel et al. 2001) for discussion). Because we have previously found that scopolamine attenuates priming in a word-stem completion paradigm (Thiel et al. 2001), the present finding, that scopolamine also impairs priming in a face recognition paradigm, confirms again that cholinergic systems are important for the behavioral expression of repetition priming.

Even if we cannot present a conclusive account why scopolamine but not lorazepam impaired repetition priming in this paradigm, our second experiment at least suggests that scopolamine's impairments of repetition priming are caused by interference with the acquisition processes as the drug impaired priming performance when it was given before but not after the study phase. Such effects on acquisition processes are in line with previous psychopharmacological studies using explicit learning paradigms where impairments of acquisition rather than retrieval of information with scopolamine have been shown (Rosier et al. 1998; Petersen 1977; Ghoneim and Mewaldt 1977).

\section{Imaging}

Fusiform Fame Responses. Our results in the placebo group replicate previous findings that showed greater responses to famous than to unfamous faces in bilateral fusiform cortex (Henson et al. 2000). A group comparison revealed weaker responses in the left fusiform region after scopolamine and lorazepam. This drug-induced 
fusiform modulation is in line with a previous PET study showing a GABAergic and cholinergic modulation of fusiform responses. Thus, a long-term reduction of fusiform activity during shape recognition was found when either scopolamine or the GABAergic agonist diazepam were given at a three day preceding encoding phase (Rosier et al. 1999; Rosier et al. 1997).

The left fusiform cortex has been shown to be involved in picture and object naming tasks (Moore and Price 1999; Murtha et al. 1999). Less activity in this region during drug challenge in our face recognition paradigm might suggest deficits in face naming. As volunteers were only required to indicate whether the face was famous or not, without concurrent naming, we cannot present behavioral data that address this issue. A prior study does suggest, however, that scopolamine can induce deficits in object naming (Aarsland et al. 1994).

An alternative explanation for reduced fusiform activity is a possible drug-induced modulation of attention. Covert visual attention can increase responses to faces in bilateral fusiform regions (Wojciulik et al. 1998; Vuilleumier et al. 2001). As both drugs increased subjective ratings of sedation, it might be argued that the lower signal changes in the left fusiform cortex are caused by reduced attention in scopolamine- and lorazepam-treated subjects. If this were the case, however, then reduced attention should have decreased fusiform responses bilaterally. The right fusiform cortex responses did not differ, however, between placebo and drug groups that would argue against an attentional account.

Fusiform Fame by Repetition Interaction. Findings in the placebo group replicate previous interactions between fame and repetition in right fusiform cortex. The voxels showing this fame by repetition interaction were close to (but did not overlap with) the region(s) previously identified by Henson et al. $(2000,2002)$. Nevertheless fusiform cortex repetition suppression was again found for famous faces. The reduced response to repetition of famous faces is consistent with "abstractionist" theories of repetition priming, which predict priming only for stimuli with preexisting representations (Tenpenny 1995; Bowers 2000).

Repetition suppression in right fusiform cortex was also observed in subjects treated with lorazepam, which showed intact repetition priming of famous faces. On the other hand, no significant repetition suppression (though a numerical reduction in activations to the second presentation of a famous face) was observed under scopolamine, which impaired priming of famous faces. Right fusiform repetition suppression thus seems to mirror the concurrent behavioral measure of priming in this face recognition paradigm, as only placebo and lorazepam groups, which showed behavioral priming of famous faces, showed significant repetition suppression in this brain area. Further studies are needed, how- ever, to investigate in more detail the cholinergic modulation of repetition suppression in right fusiform cortex in this paradigm.

\section{CONCLUSIONS}

The main finding of this study is that scopolamine but not lorazepam modulates the behavioral index of repetition priming when using a face-priming paradigm. These cholinergic impairments of repetition priming are probably caused by interference with acquisition processes. The imaging results suggest that impairments of famous face priming co-occur with reduced repetition suppression in right fusiform cortex. Furthermore, the lack of priming impairments with lorazepam in the present paradigm indicates that different priming tasks may rely on different neuronal or neurochemical systems.

\section{ACKNOWLEDGMENTS}

We thank the radiographers at the FIL for help with fMRI scanning and medical colleagues for help with injections. This work was supported by a program grant from the Wellcome Trust to RJD, a Wellcome Trust Fellowship to RNAH, and a research grant from the German Research Foundation (DFG) to CMT.

\section{REFERENCES}

Aarsland D, Larsen JP, Reinvang I, Aasland AM (1994): Effects of cholinergic blockade on language in healthy young women. Implications for the cholinergic hypothesis in dementia of the Alzheimer type. Brain 117:13771384

Badgaiyan RD (2000): Neuroanatomical organization of perceptual memory: an fMRI study of picture priming. Hum Brain Mapp 10:197-203

Bentin S, Moscovitch M (1988): The time course of repetition effects for words and unfamiliar faces. J Exp Psychol Gen 117:148-160

Bond A, Lader M (1974): The use of analogue scales in rating subjective feelings. Br J Med Psychol 47:211-218

Bowers JS (2000): In defense of abstractionist theories of repetition priming and word identification. Psychonomic Bulletin and Review 7:83-99

Brown MW, Brown J, Bowes JB (1989): Absence of priming coupled with substantially preserved recognition in lorazepam-induced amnesia. Q J Exp Psychol A 41:599617

Brunas-Wagstaff J, Young AW, Ellis AW (1992): Repetition priming follows spontaneous but not prompted recognition of familiar faces. Q J Exp Psychol A 44:423-454

Buckner RL, Goodman J, Burock M, Rotte M, Koutstaal W, Schacter D, Rosen B, Dale AM (1998): Functional-ana- 
tomic correlates of object priming in humans revealed by rapid presentation event-related fMRI. Neuron 20: 285-296

Buckner RL, Koutstaal W, Schacter DL, Rosen BR (2000): Functional MRI evidence for a role of frontal and inferior temporal cortex in amodal components of priming. Brain 123:620-640

Buffett-Jerrott SE, Stewart SH, Teehan MD (1998): A further examination of the time-dependent effects of oxazepam and lorazepam on implicit and explicit memory. Psychopharmacol 138:344-353

Clarys D, Isingrini M, Haerty A (2000): Effects of attentional load and ageing on word-stem and word-fragment implicit memory tasks. Eur J Cog Psychol 12:395-412

Curran HV, Schifano F, Lader MH (1991): Models for memory dysfunction? A comparison of the effects of scopolamine and lorazepam on memory, psychomotor performance and mood. Psychopharmacol 103:83-90

Curran HV, Pooviboonsuk P, Dalton JA, Lader MH (1991): Differentiating the effects of centrally acting drugs on arousal and memory: an event-related potential study of scopolamine, lorazepam and diphenhydramine. Psychopharmacol 135:27-36

Danion JM, Peretti S, Grange D, Bilik M, Imbs JL, Singer L (1992): Effects of chlorpromazine and lorazepam on explicit memory, repetition priming and cognitive skill learning in healthy volunteers. Psychopharmacol 108: 345-351

Danion JM, Zimmermann MA, Willard-Schroeder D, Grange D, Welsch M, Imbs JL, Singer L (1990): Effects of scopolamine, trimipramine and diazepam on explicit memory and repetition priming in healthy volunteers. Psychopharmacol 102:422-424

Desimone R (1996): Neural mechanisms for visual memory and their role in attention. Proc Natl Acad Sci USA 93:13494-13499

Ebert U, Siepmann M, Oertel R, Wesnes KA, Kirch W (1998): Pharmacokinetics and pharmacodynamics of scopolamine after subcutaneous administration. J Clin Pharmacol 38:720-726

Ellis AW, Young AW, Flude BM (1990): Repetition priming and face processing: priming occurs within the system that responds to the identity of a face. Q J Exp Psychol A 42:495-512

Friston KJ, Holmes AP, Worsely KP, Poline J-B, Frith CD, Frackowiak RSJ (1995): Statistical parametric maps in functional imaging: a general linear approach. Human Brain Mapp 2:189-210

Gabrieli JD, Vaidya CJ, Stone M, Francis WS, ThompsonSchill SL, Fleischman DA, Tinklenberg JR, Yesavage JA, Wilson RS (1999): Convergent behavioral and neuropsychological evidence for a distinction between identification and production forms of repetition priming. J Exp Psychol Gen 128:479-498

Ghoneim MM, Mewaldt SP (1977): Studies on human memory: the interactions of diazepam, scopolamine, and physostigmine. Psychopharmacol 52:1-6

Giersch A, Boucart M, Danion JM, Vidailhet P, Legrand F (1995): Effects of lorazepam on perceptual integration of visual forms in healthy volunteers. Psychopharmacol 119:105-114
Gorno-Tempini ML, Price CJ, Josephs O, Vandenberghe R, Cappa SF, Kapur N, Frackowiak RS, Tempini ML (1998): The neural systems sustaining face and propername processing. Brain 121:2103-2118

Goshen-Gottstein Y, Ganel T (2000): Repetition priming for familiar and unfamiliar faces in a sex-judgment task: evidence for a common route for the processing of sex and identity. J Exp Psychol Learn Mem Cogn 26:11981214

Green JF, McElholm A, King DJ (1996): A comparison of the sedative and amnestic effects of chlorpromazine and lorazepam. Psychopharmacology (Berl) 128:67-73

Henson R, Shallice T, Dolan R (2000): Neuroimaging evidence for dissociable forms of repetition priming. Science 287:1269-1272

Henson RNA, Shallice T, Gorno-Tempini ML, Dolan RJ (2002): Face repetition effects in implicit and explicit memory tests as measured by fMRI. Cereb Cortex 12: 178-186

Josephs O, Henson RN (1999): Event-related functional magnetic resonance imaging: modelling, inference and optimization. Philos Trans R Soc Lond B Biol Sci 354:12151228

Knopman D (1991): Unaware learning versus preserved learning in pharmacologic amnesia: similarities and differences. J Exp Psychol Learn Mem Cogn 17:1017-1029

Legrand F, Vidailhet P, Danion JM, Grange D, Giersch A, van der Linden M, Imbs JL (1995): Time course of the effects of diazepam and lorazepam on perceptual priming and explicit memory. Psychopharmacol 118:475-479

Martinez R, Molchan SE, Lawlor BA, Thompson K, Martinson H, Latham G, Weingartner H, Sunderland T (1997): Minimal effects of dextroamphetamine on scopolamineinduced cognitive impairments in humans. Biol Psychiatry 41:50-57

Moore CJ, Price CJ (1999): Three distinct ventral occipitotemporal regions for reading and object naming. Neuroimage 10:181-192

Murtha S, Chertkow H, Beauregard M, Evans A (1999): The neural substrate of picture naming. J Cogn Neurosci 11:399-423

Nuotto E (1983): Psychomotor, physiological and cognitive effects of scopolamine and ephedrine in healthy man. Eur J Clin Pharmacol 24:603-609

Petersen RC (1977): Scopolamine induced learning failures in man. Psychopharmacol 52:283-289

Putcha L, Cintron NM, Tsui J, Vanderploeg JM, Kramer WG (1989): Pharmacokinetics and oral bioavailability of scopolamine in normal subjects. Pharm Res 6:481-485

Rammsayer TH, Rodewald S, Groh D (2000): Dopamineantagonistic, anticholinergic, and GABAergic effects on declarative and procedural memory functions. Cogn Brain Res 9:61-71

Rosier A, Cornette L, Dupont P, Bormans G, Michiels J, Mortelmans L, Orban GA (1997): Positron- emission tomography imaging of long-term shape recognition challenges. Proc Natl Acad Sci USA 94:7627-7632

Rosier A, Cornette L, Orban GA (1998): Scopolamineinduced impairment of delayed recognition of abstract visual shapes. Neuropsychobiol 37:98-103 
Rosier AM, Cornette L, Dupont P, Bormans G, Mortelmans L, Orban GA (1999): Regional brain activity during shape recognition impaired by a scopolamine challenge to encoding. Eur J Neurosci 11:3701-3714

Safer DJ, Allen RP (1971): The central effects of scopolamine in man. Biol Psychiatry 3:347-355

Sannita WG, Fioretto M, Maggi L, Rosadini G (1987): Effects of scopolamine parenteral administration on the electroretinogram, visual evoked potentials, and quantitative electroencephalogram of healthy volunteers. Doc Ophthalmol 67:379-388

Schacter DL (1994). Priming and multiple memory systems: perceptual mechanisms of implicit memory. In Schacter DL, Tulving E (eds), Memory Systems. Cambridge, MA: MIT Press, pp. 233-268

Schifano F, Curran HV (1994): Pharmacological models of memory dysfunction? A comparison of the effects of scopolamine and lorazepam on word valence ratings, priming and recall. Psychopharmacol 115:430-434

Schweinberger SR, Pfuetze EM, and Sommer W (1995): Repetition priming and associative priming of face recognition: evidence from event-related potentials. J Exp Psychol (Learn Mem Cog) 21:722-736.

Squire LR, Ojemann JG, Miezin FM, Petersen SE, Videen TO, Raichle ME (1992): Activation of the hippocampus in normal humans: a functional anatomical study of memory. Proc Natl Acad Sci USA 89:1837-1841

Sunderland T, Tariot PN, Cohen RM, Weingartner H, Mueller EA.III, and Murphy DL (1987): Anticholinergic sensitivity in patients with dementia of the Alzheimer type and age-matched controls: a dose-response study. Arch. Gen.Psychiatry 44:418-426.

Tenpenny PL (1995): Abstractionist versus episodic theories of repetition priming and word identification. Psych. Bull Rev 2:339-363

Thiel CM, Henson RA, Morris JS, Friston KJ, Dolan RJ (2001): Pharmacological modulation of behavioural and neuronal correlates of repetition priming. J Neurosci 21:6846-6852

Tsukada H, Kakiuchi T, Ando I, Shizuno H, Nakanishi S, Ouchi Y (1997): Regulation of cerebral blood flow response to somatosensory stimulation through the cholinergic system: a positron emission tomography study in unanesthetized monkeys. Brain Res 749:10-17

van Turennout M, Ellmore T, Martin A (2000): Long-lasting cortical plasticity in the object naming system. Nat Neurosci 3:1329-1334

Vidailhet P, Danion JM, Chemin C, Kazes M (1999): Lorazepam impairs both visual and auditory perceptual priming. Psychopharmacol 147:266-273

Vidailhet P, Danion JM, Kauffmann-Muller F, Grange D, Giersch A, van der Linden M, Imbs JL (1994): Lorazepam and diazepam effects on memory acquisition in priming tasks. Psychopharmacol 115:397-406

Vitiello B, Martin A, Hill J, Mack C, Molchan S, Martinez R, Murphy DL, Sunderland T (1997): Cognitive and behavioral effects of cholinergic, dopaminergic, and serotonergic blockade in humans. Neuropsychopharmacol 16:15-24

Vuilleumier P, Armony JL, Driver J, Dolan RJ (2001): Distinct effects of attention and emotion on face processing in the human brain: an event-related fMRI study. Neuron 30:829-841

Wojciulik E, Kanwisher N, Driver J (1998): Covert visual attention modulates face-specific activity in the human fusiform gyrus: fMRI study. J Neurophysiol 79:1574-1578 